Kompass

Neumología

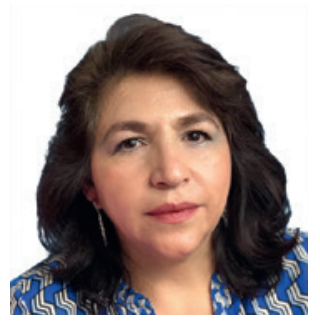

\section{Ma. del Rocío García-Olvera}

Neumóloga Pediatra,

Ciudad de México, CDMX, México

\title{
La pediatría en tiempos de SARS-CoV2 (COVID-19)
}

«Me afecta cualquier amenaza contra el hombre, contra la familia y la nación. Amenazas que tienen siempre su origen en nuestra debilidad humana, en la forma superficial de considerar la vida.»

Papa Juan Pablo II

La pandemia por COVID-19 ha generado cambios importantes en la actividad científica desde su aparición en diciembre del 2019, el darse a conocer el genoma del virus el 12 enero y la declaración en marzo del 2020 de Pandemia. La producción inmediata de vacunas, la búsqueda de nuevos tratamientos; estudio de las alteraciones sistémicas que deja la infección y tratar de limitarlas, la lucha por disminuir la mortalidad por este virus. Mejorar la economía buscando la reactivación laboral [1, 2].

El trabajo de la comunidad científica no se ha detenido en tratar de proporcionar los conocimientos necesarios que permitan dar un manejo unificado al paciente por COVID-19, sin embargo, se ha visto disminuida la producción científica en otras patologías. Se han modificado las estructuras de los hospitales para proporcionar atención prioritaria a pacientes por COVID-19 y de manera inicial se ha desprotegido a otros enfermos, se han creado nuevos modelos de atención (protocolos) en los servicios de pediatría, la cual ha permitido la regionalización de los tratamientos [1, 2].

Con la ingeniería genética se han desarrollado en el mundo más de 200 gamas de vacunas estando en aplicación una decena de ellas con tecnologías nuevas, como las creadas por Pfizer/BioNTech (EE. UU./Alemania) tecnología ARNm en dos dosis, y de la cual se tiene mayor experiencia en uso a todas las edades ya que en la actualidad los Estados Unidos han autorizado el 12 de mayo de este año su aplicación en mayores de 12 años, que abre una oportunidad a la detención de la pandemia, otras de las vacunas que se están suministrando son la de Moderna con la misma tecnología que la de Pfizer/BioNTech, AstraZeneca (Oxford, Reino Unido) la cual no ha tenido mucha aceptación en la Unión europea por la aparición de casos de trombosis relacionadas con la respuesta inmunológica del huésped a la vacuna. La vacuna Rusa Sputnik en la cual se utiliza un adenovirus con una efectivad similar a las previas y que se suministra en 2 dosis, y las vacunas chinas las cuales son CanSino, Sinopharm y Sinovac, considerándose una efectividad menora a las otras [3]. Ahora con la aparición de nuevas cepas resultado de las mutaciones en diferentes países, Reino Unido, Sudáfrica y Brasil la pregunta que se hace la comunidad científica, ¿si las vacunas actuales pueden combatirlas o habrá que generar nuevas vacunas? Hasta el momento no se tiene la respuesta, pero se considera que las vacunas de Pfizer y Moderna por su técnica de RNAm y la versatilidad que les confieren pueden modificarse a las nuevas cepas mutadas [4]. El comportamiento en pediatría de la afección por COVID-19, en la mayoría de los casos cursa asintomática siendo un vector im- 
portante para la transmisión de la enfermedad, debido que un niño puede llegar a infectar hasta 8 adultos, de manera inicial no se detectaron muertes, fue hasta los meses de abril y mayo del 2020 que las asociaciones pediátricas y de cuidados intensivos en Italia, España y Reino Unido emiten una alerta por un incremento en los casos de enfermedad de Kawasaki incompletos o atípicos con mayor resistencia a la gammaglobulina intravenosa, denominándose por la OMS como Síndrome Inflamatorio Sistémico (SIM/MIS) en niños y adolescentes de

\section{Referencias}

1 Mishra SK, Tripathl T: One-year update on the COVID-19 pandemic: Where are we now? Acta Trop. 2021 Feb;214:105778.

2 Liu W, Zhang Q, Chen J, et al.: Detection of Covid-19 in children in early January 2020 in Wuhan, China. N Engl J Med. 2020;382:13701371.

3 Prync SA: Vacunas para SARS-CoV-2, diferentes estrategias de los desarrollos en curso. RevHosp Ital B Aires. 2020;40(1):1-12.
0-19 años, asociado a COVID-19, que cursen con fiebre mayor de 3 días y cumplan con 2 de los criterios establecidos que forman parte del cuadro de enfermedad de Kawasaki $[5,6]$.

Estos 18 meses de pandemia ha cambiado al mundo, en todos los aspectos como lo social, económico y cultural provocando en muchos países un impacto catastrófico a la economía. Consideraría un pago a los avances tecnológicos, la comunicación aérea que ha hecho se propague con mayor rapidez, tendremos que adaptarnos a esta nueva forma de vida, probablemente las escuelas no sean del todo presenciales, y el socializar sufra cambios importantes y nuestra convivencia siga siendo a través de un cubrebocas y sana distancia que han demostrado hasta el momento ser eficaces.

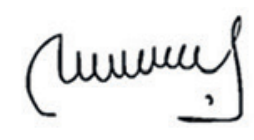

Dra. Ma. del Rocío García Olvera
4 Wang R, Hozumi Y, Yin C: Mutations on COVID-19 diagnostic targets. Genomics. 2020; 112:2504-5213.

5 Royal College of Paediatrics and Child Health: Guidance: paediatric multisystem inflammatory syndrome temporally associated with Disponible en: https://www.rcpch.ac.uk/resources/guidancepaediatric-multisystem-inflammatory-syndrome-temporallyassociated-covid19-pims (último acceso 22 de Mayo 2020).
6 Verdoni L, Mazza A, Gervasoni A: An outbreak of severe Kawasaki-like disease at the Italian epicentre of the SARS-CoV-2 epidemic: an observational cohort study. Lancet. 2020;395(10239):1771-1778. 